\title{
Bi Catalyzed CdS Nanowires With Temperature-Dependent Morphologies for Potential Applications in Solar Cells
}

\section{P. G. Zayas-Bazán ${ }^{1}$, K. Gutierrez Z-B ${ }^{1}$, O. de Melo ${ }^{1,2,3}$, G. Santana ${ }^{3}$, J. Sastré-Hernández ${ }^{1}$, J. R. Aguilar-Hernández ${ }^{1}$, M. Tufiño-Velázquez ${ }^{1}$ and G. Contreras-Puente $^{1 *}$}

${ }^{1}$ Escuela Superior de Física y Matemáticas, Instituto Politécnico Nacional, Mexico City, Mexico, ${ }^{2}$ Physics Faculty, University of Havana, Colina Universitaria, Havana, Cuba, ${ }^{3}$ Instituto de Investigación en Materiales, Universidad Nacional Autónoma de México, Cd. Universitaria, Coyoacán, Mexico

In this work, we present the preparation of CdS nanowires (CdS NWs) using the chemical vapor deposition technique and bismuth (Bi) nanoparticles as catalysts. The obtained nanowires were found to be in the hexagonal Greenockite structure according to XRD diffractograms and Raman spectroscopy measurements. Depending on the growth temperature, two kinds of morphologies were observed in SEM images. At low temperature (around $150^{\circ} \mathrm{C}$ ), a high density and homogeneous population of thin and straight nanowires grown through the vapor-liquid-solid mechanism was observed. At higher temperature (around $270^{\circ} \mathrm{C}$ ), thicker bunches of braided nanowires were observed. A quantitative analysis of the temperature-dependent photoluminescence spectra of the CaS NWs was carried out.

Keywords: solar cells, semiconductors, nanowires, photoluminescence, catalytic method

\section{INTRODUCTION}

Semiconductor nanowires have been the subject of intense research because of their novel properties and potential to be incorporated in advanced devices. They exhibit fast $1 \mathrm{D}$ growth rate with good crystalline quality, thus leading to advantages in efficiencies and costs (Cui and Lieber, 2001; Huang et al., 2001a; Lieber, 2003; Tang et al., 2011) in opto-electronic devices. CdS nanowires (CdS NWs) used as window material in p-n junction solar cells have the advantage of increasing the effective $\mathrm{p}-\mathrm{n}$ interface, thus reducing the losses due to photo-carrier recombination and increasing light trapping as well (Liu et al., 2011). Taking this into account, we propose a solar cell with the configuration shown in Figure 1. On the other hand, this nanostructured CdS could be tested as windows material (or even as absorber) in hybrid solar cells, like Quantum Dots Dye Sensitized Solar Cell (QD-DSSC), CdTe, or colloidal CdSeTe. Our argument is supported by the fact that the space in between the nanowires could be embedded by an organic or inorganic photo-absorbent, or micro crystals (Wang et al., 2007; Lee et al., 2009; Grynko et al., 2015). Besides, the incorporation of CdS NWs could have the advantage of providing a direct path for the electrons to the anode, thus decreasing the recombination of photoexcited electrons with the electrolyte (Jasim, 2011; Pan et al., 2018) as a consequence of hopping between nanocrystals as occurs in DSSC cells. Other works carried out in recent years report the use of CdS NWs, combined with other materials such as $\mathrm{ZnO}, \mathrm{TiO}_{2}$, and $\mathrm{Pt}$ to produce photocatalytic hydrogen under visible light irradiation. In these cases, the CdS NWs showed an efficient charge separation, caused by fast diffusion of the generated 


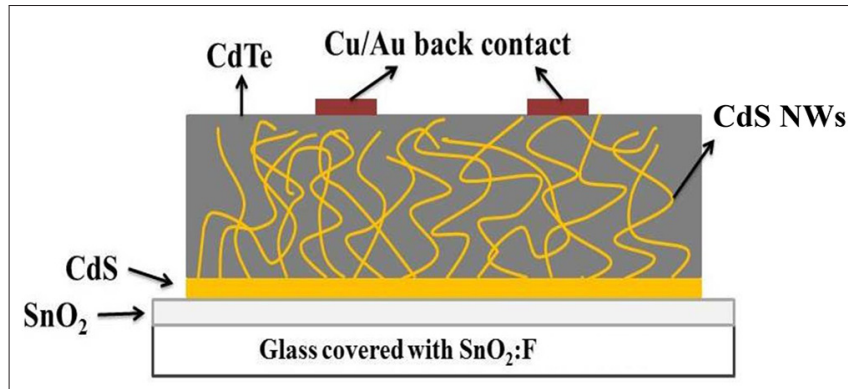

FIGURE 1 | Scheme of a prototype of solar cell using CdS nanowires.

photoelectrons, becoming an excellent highly active photocatalyst for the production of hydrogen (Bao et al., 2006; Jang et al., 2008; Barpuzary et al., 2011).

Chemical vapor deposition (CVD) technique, assisted or not by metal catalysts (nanoparticles or very thin layers) is frequently used for preparing CdS NWs (Wang et al., 2002a; Ge and Li, 2004; Kwak et al., 2009). They are obtained by transport of the vapor species to the substrates covered with the catalyst. Different growth mechanisms have been found to be involved in the formation of nanostructures, the most characteristic being the vapor-liquid-solid (VLS) one (Givargizov, 1975; Kolasinski, 2006; Grynko et al., 2013). According to this mechanism, the metal catalyst forms a drop in which vapor species dissolve until oversaturation; then, the excess material precipitates and the nanowire forms with a drop at the tip.

Nanoparticles or very thin layers of gold are more frequently used as catalyst for the growth of nanowires (Huang et al., 2001b; Wang et al., 2002b; Fu et al., 2006; Ma et al., 2007; Zervos and Othonos, 2011). However, Au melting temperature or $\mathrm{Au} / \mathrm{Cd}$ eutectic $\left(1,064\right.$ and $500^{\circ} \mathrm{C}$, respectively) are both quite high. In addition, $\mathrm{Au}$ has been found to form non-radiative recombination centers in CdS that degrade the optical properties of the nanowires (Schmidt et al., 2009). Bismuth appears to be a suitable catalyst candidate for the preparation of CdS NWs due to its low melting temperature of $271^{\circ} \mathrm{C}$ and because it forms a eutectic with $\mathrm{Cd}$ at $145^{\circ} \mathrm{C}$ (Keşlioglu et al., 2004). In the last few years, the preparation of nanostructures of several semiconductor materials using $\mathrm{Bi}$ as a catalytic metal has been reported (Wang et al., 2006; Ouyang et al., 2007; Sun and Buhro, 2008; Kwak et al., 2009, 2010). In these cases, the nanostructures were obtained using a thin layer of $\mathrm{Bi}$; the solution-liquid-solid mechanism (SLS) has been verified. The use of a relatively large amount of chemicals in SLS growth, with the subsequent generation of byproducts during the process, can work against the purity of the prepared material. In contrast, CVD CdS is characterized by a high degree of purity since only CdS vapor species and $\mathrm{H}_{2}$ are present in the growth reactor.

In this work, we used Bi nanoparticles (NPs) to catalyze the growth of CdS NWs. Because of the low temperature of the $\mathrm{Cd} / \mathrm{Bi}$ eutectic point, we obtained CdS NWs through the VLS mechanism in a CVD configuration at substrate temperatures as low as $145^{\circ} \mathrm{C}$. After careful calibration experiments, the flux and the type of gas carrier were found to be determinant for obtaining the growth of nanowires in the VLS regime. Independent of the substrate temperature, two different kinds of morphologies

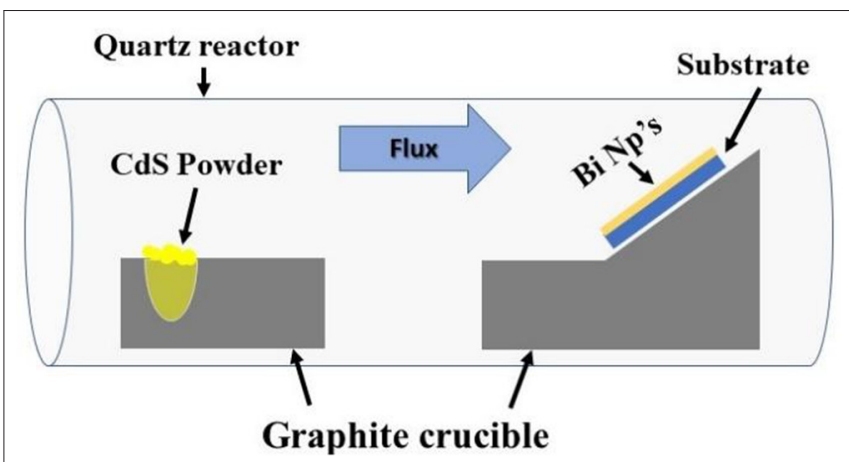

FIGURE 2 | Experimental setup used to grow CdS Nws. The source and substrate are located in two graphite crucibles inside a quartz reactor.

were obtained, and their origin is discussed in relation with the growth parameters.

\section{EXPERIMENTAL}

Soda-lime glasses with a fluorine-doped tin oxide layer (TEC15, according to the manufacturer nomenclature, Pilkington, St Helens, United Kingdom) are covered using a triple-magnetron RF-Sputtering (model V3, Intercovamex, Mexico City, Mexico), with layers of sputtered undoped $\mathrm{SnO}_{2}(35 \mathrm{~nm})$ and $\mathrm{CdS}(60 \mathrm{~nm})$ and were used as substrates. In a typical experiment, $10 \mu \mathrm{l}$ of a suspension composed of $20 \mathrm{~g}$ of Bi nanoparticles (NPs) dispersed in $10 \mathrm{ml}$ of methanol was spin-coated onto the substrate at $1,000 \mathrm{rpm}$ for $30 \mathrm{~s}$. Then, the substrate was heated at $70^{\circ} \mathrm{C}$ for $1 \mathrm{~min}$, allowing the methanol to evaporate. CdS powder (Aldrich 99.999\% purity) was located in a graphite boat in the highest temperature region $\left(800^{\circ} \mathrm{C}\right)$ of a tubular furnace inside a quartz reactor. Initially, a nitrogen flow of $0.6 \mathrm{~L} / \mathrm{min}$ was established to remove the air in the reactor. Afterwards, the system was flowed with forming gas $\left(80 \% \mathrm{Ar} / 20 \% \mathrm{H}_{2}\right)$ at atmospheric pressure at a rate of $0.1 \mathrm{~L} / \mathrm{min}$. Downstream, at a coldest region in the reactor ( 150 or $270^{\circ} \mathrm{C}$ for samples $\mathrm{A}$ and $\mathrm{B}$, respectively), the substrate with the NPs was located (see Figure 2). The growth time was $10 \mathrm{~min}$ and, once the process was finished, the system was cooled down under $\mathrm{N}_{2}$ flow.

Scanning electron microscopy (SEM) images and energy dispersed spectroscopy (EDS) were obtained with a JSM 7800F JEOL system (Kyoto, Japan) while TEM images were obtained with a JEM-ARM200CF microscope provided with a cold cathode electron gun (Cold Field Emission Gun, CFEG), a spherical aberration corrector CEOS. The x-ray diffractograms were taken with an X'Pert PRO PANalytical diffractometer (Almelo, Netherlands) in fixed grazing incidence angle at room temperature and using $\mathrm{Cu}-\mathrm{K} \alpha$ radiation $(\lambda=1.54056 \AA)$. Raman spectra were measured with a Labram HR800 (Horiba Jobin Yvon, Kyoto, Japan) equipment, with an excitation line of $633 \mathrm{~nm}$ with an output power of $10.7 \mu \mathrm{W}$ and objective magnification of $50 \times$. Photoluminescence (PL) spectra were obtained using a $\mathrm{He}-\mathrm{Cd}$ laser with an excitation wavelength of $442 \mathrm{~nm}$ and output power of $16 \mathrm{~mW}$ at room temperature. A double monochromator SPEX-1403 was used to obtain the photoluminescence spectra and the signal was detected using a thermoelectrically cooled 
photomultiplier RCA-C31034 that is coupled to a photon counter equipment. In other experiments, a 325-nm laser line was used as the excitation source and the sample emission was focused into a photomultiplier tube of an Acton SpectraPro 2500i spectrograph. All the spectra were corrected taking into account the spectral response of the system. No significant differences were found in the spectra that were taken with the two configurations.

\section{RESULTS AND DISCUSSION}

A secondary electron SEM image of the obtained nanowire forest observed in a typical region of the surface of the sample $\mathrm{A}$ is shown in Figure 3A. A high density and a homogeneous population of thin nanowires with straight morphology can be appreciated. In Figure 4, a low-resolution TEM image displays a nanowire around $50 \mathrm{~nm}$ thick, with a dark sphere at the tip, which we associate to a bismuth nanoparticle. At the left inset in Figure 4, a high-resolution TEM image allows one to appreciate the crystalline planes in the body of the nanowire. The measurement of the inter-planar distance of these planes indicates that the axial direction of the nanowire coincides with [100] crystalline direction, as frequently observed in CdS NWs (Fu et al., 2006). The nanowires are single crystals as can be observed in the corresponding Fast Fourier Transform in the right inset in Figure 4, which can be indexed as the [001] zone axis; thus, the nanowires grow with the [001] direction normal to the axis of the nanowires. Figure $\mathbf{3 B}$ shows an image obtained with the backscattered electron detector, which allows one to better resolve differences in chemical compositions. In this figure, small bright spots with spherical shape distributed throughout the sample surface and located at the tip of the nanowires can be appreciated. These bright spots were identified as $\mathrm{Bi}$ according to the EDS spectrum shown in the inset of Figure 3B. This is an indication that the VLS mechanism is responsible for the formation of the nanowires.

The nanowire morphology obtained at a higher substrate temperature of $270^{\circ} \mathrm{C}$ (sample B), is shown in Figure 3C. In this case, bunches of braided nanowires with diameters ranging between 100 and $300 \mathrm{~nm}$ are observed. Also, the nanowire density is smaller than that in sample A.

These morphology differences can be explained considering that, at the higher temperature of the sample B (near to the fusion point of $\mathrm{Bi}$ ), several Bi nanoparticles can coalesce, forming larger particles and leading to the formation of more than one nanowire in the same catalyst particle.

In the $\mathrm{X}$-ray diffractograms for both samples, shown in Figure 5A, the characteristic reflections of the CdS with Greenockite phase (PDF 41-1,049) are observed. The peaks marked with " + " come from the $\mathrm{SnO}_{2}$ substrate layer with tetragonal phase (PDF 41-1,445), and the peaks around $40^{\circ}$ correspond to the planes (104) and (110) of $\mathrm{Bi}$ with rhombohedral phase (PDF 44-1,246). The diffractogram of the substrate CdS layer was found to be very weak (see Figure S1 in the supplementary material), which indicates that the main contribution of the diffractograms presented here comes from the CdS NWs.

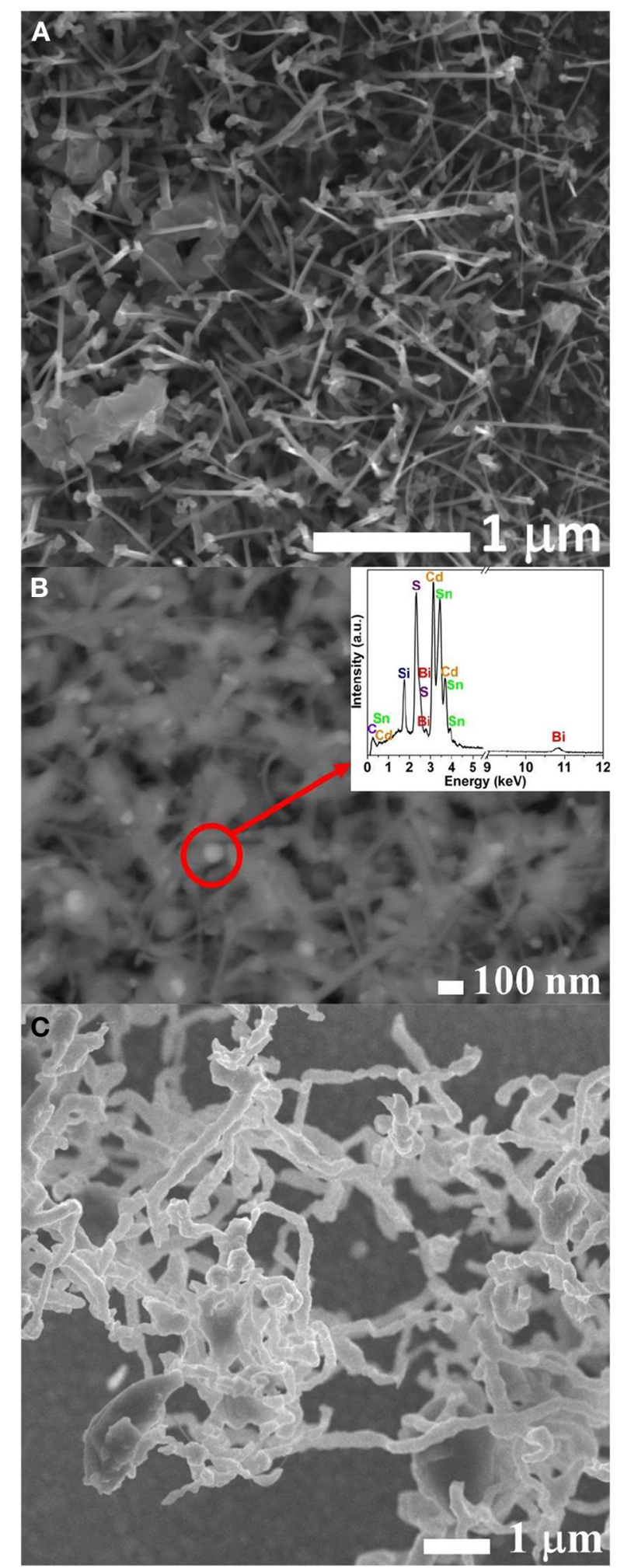

FIGURE 3 | (A) SEM images of the sample A showing a high density of CdS nanowires. (B) Backscattered electron image showing bright spots at the tip of the nanowires. In the inset, an EDS spectrum confirms the presence of $\mathrm{Bi}$ in the bright spots. (C) SEM images of the nanowires obtained in sample B with a substrate temperature of $270^{\circ} \mathrm{C}$. 
Raman spectra of samples A and B are shown in Figure 5B together with the spectrum of a target fabricated with the $\mathrm{Bi}$ nanoparticles. In the spectra, the characteristic emission of the longitudinal optical LO-mode of CdS with Greenockite phase at $300 \mathrm{~cm}^{-1}$ and its 2LO-first harmonic at $600 \mathrm{~cm}^{-1}$ can be appreciated (Nusimovici and Birman, 1967). This result confirms the indication of the $\mathrm{x}$-ray diffraction analysis. The other emissions observed in the Raman spectrum of the nanowires are

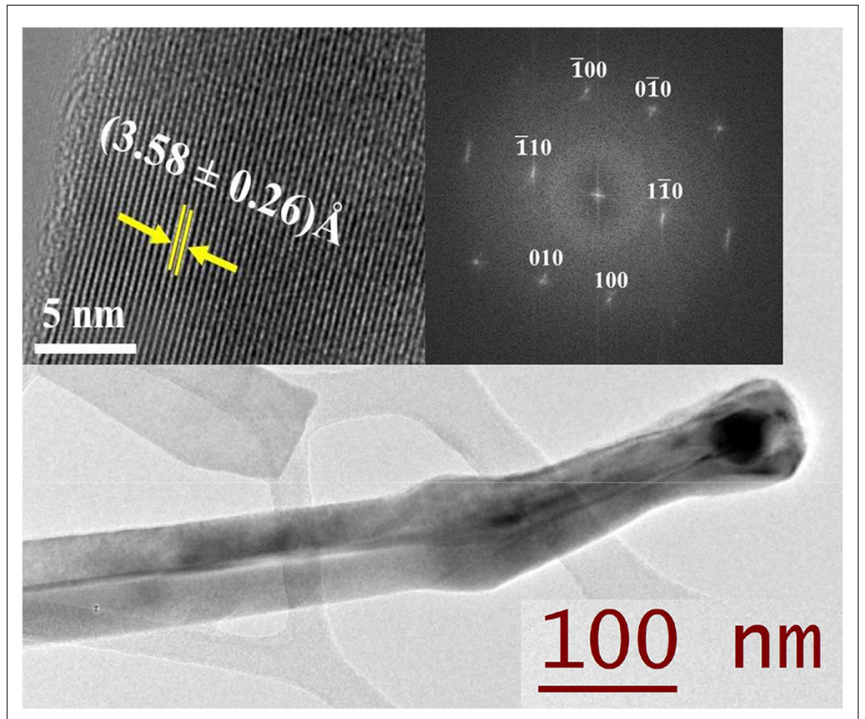

FIGURE 4 | TEM image of the nanowires at low resolution. The left inset shows a high-resolution TEM image in which it is possible to observe the crystalline planes. The Fast Fourier Transform is shown in the right inset, which can be indexed as the [001] zone axis. associated with the Bi nanoparticles: the peaks located around 97 and $185 \mathrm{~cm}^{-1}$ are the first- and second-order Raman scattering mode of bismuth in the rhombohedral structure (Lannin et al., 1975). The increase of the background intensity with increasing energy is associated to the fluorescence in the $\mathrm{SnO}_{2}$ layer of the substrate (similar background was measured in samples with only the $\mathrm{SnO}_{2}$ layer).

Photoluminescence spectra for the samples at low temperature $(12-20 \mathrm{~K})$ and room temperature $(300 \mathrm{~K})$ are shown in Figure 6. The samples showed an intense and bright luminescence with a narrow peak around $2.5 \mathrm{eV}$ at low temperature, which follows the behavior of near band gap emissions (NBE) (Yang et al., 2012). In fact, deconvolution of these spectra was carried out and the behavior of the intense peak with temperature was found to follow the Varshni equation $\left(E_{g}(T)=E_{g}(0)-\frac{\alpha T^{2}}{T+\beta}\right)$ as it can be observed in the insets, where $E_{0}$ is the low-temperature band gap and $\alpha$ and $\beta$ are the Varshni constants (Varshni, 1967) (The complete set of spectra at different temperatures and the deconvolution of the spectra at low temperature can be seen in Figure S2 and Figure S3 in the supplementary material, respectively.). Following previous reports (Thomas and Hopfield, 1962), we assigned this peak to the emission of a bound exciton to a neutral acceptor $\left(I_{1}\right)$. The NBE intense peak of sample B is much narrower than that detected for sample A and is slightly shifted. This suggests that the NBE luminescence of sample A is composed of other contributions probably related with defects. This is confirmed by the presence of an intense and wide band centered at around $2.05 \mathrm{eV}$, known as the "yellow band (YB)" of CdS that has been ascribed to donor-acceptor pairs related to relatively deep centers associated with Cd interstitial $\left(\mathrm{Cd}_{\mathrm{i}}\right)$ or $\mathrm{S}$ vacancies $\left(\mathrm{S}_{\mathrm{V}}\right)$ (Hong et al., 2000; Chandran et al., 2011). The YB has a tail at
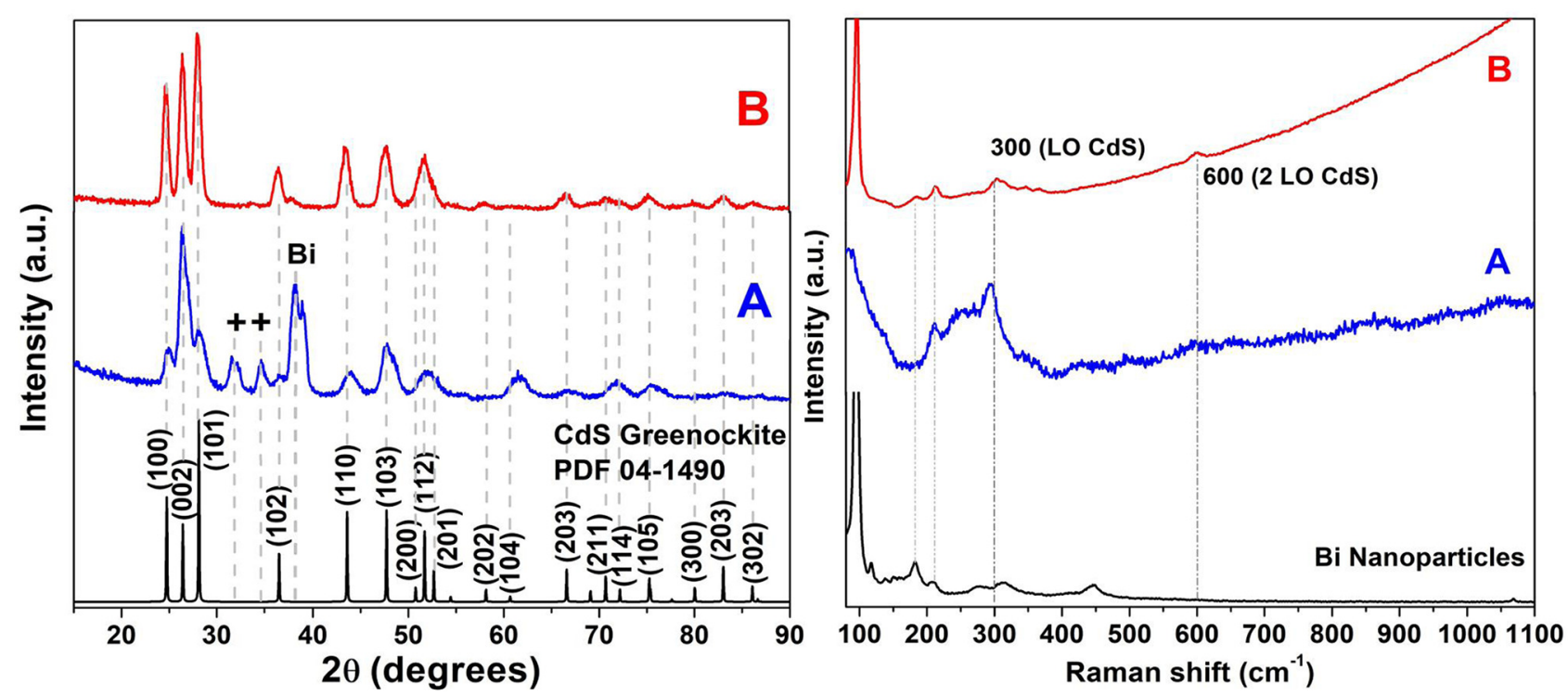

FIGURE 5 | (A) XRD diffractogram for samples A and B showing the characteristic peaks of the CdS with Greenockite phase (the peaks marked with + symbols come from the $\mathrm{SnO}_{2}$ substrate). (B) Raman spectra of nanowires and nanoparticles. The vibrational modes $1 \mathrm{LO}$ and $2 \mathrm{LO}$ corresponding to CdS with Greenockite phase are observed. 

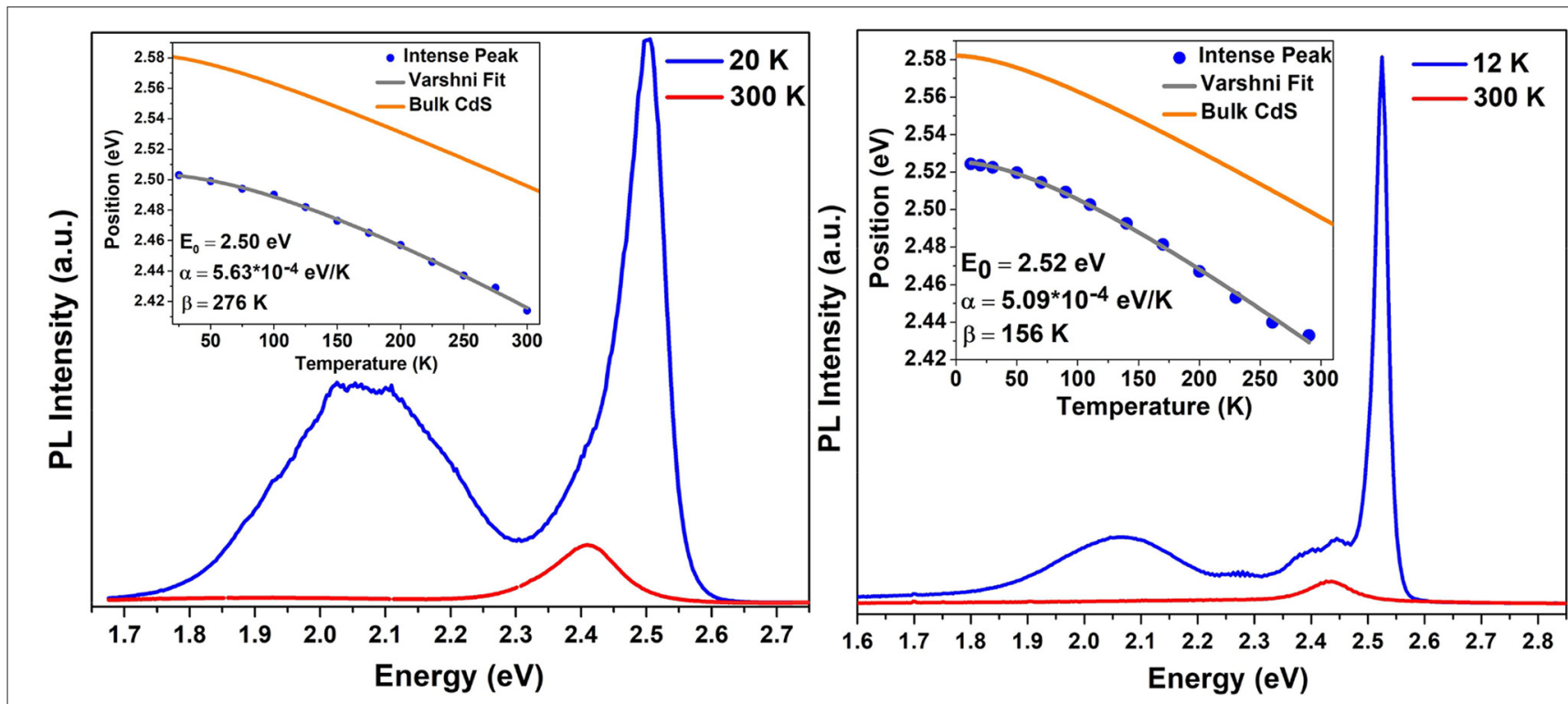

FIGURE 6 | Photoluminescence spectra at low and room temperature of (A) sample A and (B) sample B. In the inset, the fit of the NBE peak to the Varshni equation and the obtained parameters are presented.

near $1.9 \mathrm{eV}$, which can be ascribed to the red band (RB) usually related with surface defects (Shiraki et al., 1974). This combined defect band is more intense for sample A with respect to the NBE emission. At room temperature, spectra are dominated by the socalled "green band (GB)" with a high energy component peaking at near $2.4 \mathrm{eV}$, which has been related in the literature with a free to bound transition corresponding with the recombination of a free electron with a neutral acceptor $\left(\mathrm{eA}_{0}\right)$ (Colbow, 1966). The other two peaks present in the GB (resolved only in the spectra of sample B) having an energy separation near the CdS LO phonon $(0.037 \mathrm{eV})$ (Marshall and Mitra, 1964) were considered as the typical phonon replicas of the $2.4-\mathrm{eV}$ transition. According to the above PL analysis, CdS NWs in sample A seem to have a larger amount of defects. This is probably due to the larger surface-to-volume ratio (small diameter) for these nanowires. This can increase surface states as well as $\mathrm{Cd}$ vacancies. As a comparison, it is worth noting that the RT luminescence of CdS NWs grown by the SLS mechanism with Bi catalyst is dominated by the yellow band instead (Kwak et al., 2009).

It is important to consider that the bands, named $\mathrm{YB}, \mathrm{eA}_{0}$, or the unknown surface defect one, have charged state centers whose trapped charges can recombine and give place to the PL emission. The high density of trapped charge centers, originated from the non-crystalline nature of the material, is deleterious for the operation of II-VI solar cells. However, its presence is not completely unavoidable, and defects are always present in the materials, particularly when the surface-to-bulk ratio is high, like in NWs.

\section{CONCLUSIONS}

The CdS NWs were prepared using the catalytic method with Bi nanoparticles. X-ray diffractograms and Raman spectra verified the presence of CdS hexagonal phase. Depending on the growth temperature, the SEM images revealed two kinds of morphologies. At low temperature, a highly dense and homogeneous population of thin and straight nanowires with diameters $<100 \mathrm{~nm}$ was obtained. The images obtained by backscattered electrons reveal bright spots with spherical shape at the nanowire tip, indicating a VLS mechanism. At higher temperatures, bunches of braided nanowires with diameters ranging between 100 and $300 \mathrm{~nm}$ were observed. These different morphologies can be explained as a consequence of the coalescence of Bi nanoparticles at higher substrate temperature. The study of the PL showed that thin nanowires obtained at low substrate temperature seem to have larger concentration of defects probably because of the large surface-to-volume ratio. CVD CdS NWs prepared with Bi nanoparticles could be used in CdS/CdTe third-generation solar cells with advantages with respect to gold-catalyzed ones. These CdS NWs have good crystalline quality, although defect bands could affect the efficiency of the solar cell. However, we consider it not significant because, at room temperature, this band is almost no appreciable.

\section{DATA AVAILABILITY STATEMENT}

The raw data supporting the conclusions of this article will be made available by the authors, without undue reservation, to any qualified researcher on request.

\section{AUTHOR CONTRIBUTIONS}

GC-P and OM contributed to the conception and design of the experiments and also to the analysis of the results. PZ-B and KGZ-B worked on the realization of the experiments, the characterization of the samples, and analysis of the results. GS, 
JS-H, JA-H, and MT-V worked on the measurements of optical, structural, and morphological properties and also intervened in the analysis of the results. PG and OM wrote the original draft. All authors contributed to manuscript revision, read, and approved the submitted version.

\section{ACKNOWLEDGMENTS}

The authors gratefully acknowledge projects SIP-IPN-20190173, SIP-IPN-20196099, and COFAA-IPN for financial support in

\section{REFERENCES}

Bao, N., Shen, L., Takata, T., Lu, D., and Domen, K. (2006). Highly ordered Pt-loaded CdS nanowire arrays for photocatalytic hydrogen production under visible light. Chem. Lett. 35, 318-319. doi: 10.1246/cl.2 006.318

Barpuzary, D., Khan, Z., Vinothkumar, N., De, M., and Qureshi, M. (2011). Hierarchically grown urchinlike CdS@ZnO and CdS@Al2O3 heteroarrays for efficient visible-light-driven photocatalytic hydrogen generation. J. Phys. Chem. C 116, 150-156. doi: 10.1021/jp207452c

Chandran, A., Samuel, M., S., Koshy, J., and George, K. C. (2011). Correlated barrier hopping in CdS nanoparticles and nanowires. J. Appl. Phys. 109:084314. doi: $10.1063 / 1.3569744$

Colbow, K. (1966). Free-to-bound and bound-to-bound transitions in CdS. Phys. Rev. 141:742. doi: 10.1103/PhysRev.141.742

Cui, Y., and Lieber, C. M. (2001). Functional nanoscale electronic devices assembled using silicon nanowire building blocks. Science 291, 851-853. doi: 10.1126/science.291.5505.851

Fu, X. L., Li, L. H., and Tang, W. H. (2006). Preparation and characterization of CdS/Si coaxial nanowires. Solid State Commun. 138, 139-142. doi: 10.1016/j.ssc.2006.02.015

Ge, J., and Li, Y. (2004). Selective atmospheric pressure chemical vapor deposition route to CdS arrays, nanowires, and nanocombs. Adv. Funct. Mater. 14, 157-162. doi: 10.1002/adfm.200305051

Givargizov, E. I. (1975). Fundamental aspects of VLS growth. J. Cryst. Growth. 31, 20-30. doi: 10.1016/0022-0248(75) 90105-0

Grynko, D. A., Fedoryak, A. N., Dimitriev, O. P., Lin, A., Laghumavarapu, R. B., and Huffaker, D. L. (2013). Growth of CdS nanowire crystals: vaporliquid-solid versus vapor-solid mechanisms. Surf. Coat. Technol. 230, 234-238. doi: 10.1016/j.surfcoat.2013.06.058

Grynko, D. O., Fedoryak, O. M., Smertenko, P. S., Ogurtsov, N. A., Pud, A. A., Noskov, Y. V., et al. (2015). Multifunctional role of nanostructured CdS interfacial layers in hybrid solar cells. J. Nanosci. Nanotechnol. 15, 752-758. doi: 10.1166/jnn.2015.9171

Hong, K. J., Jeong, T. S., Yoon, C. J., and Shin, Y. J. (2000). The optical properties of CdS crystal grown by the sublimation method. J. Cryst. Growth. 218, 19-26. doi: 10.1016/S0022-0248(00)00491-7

Huang, M. H., Mao, S., Feick, H., Yan, H., Wu, Y., Kind, H., et al. (2001a). Room-temperature ultraviolet nanowire nanolasers. Science 292, 1897-1899. doi: 10.1126/science.1060367

Huang, M. H., Wu, Y., Feick, H., Tran, N., Weber, E., and Yang, P. (2001b). Catalytic growth of zinc oxide nanowires by vapor transport. Adv. Mater. 13, 113-116. doi: 10.1002/1521-4095(200101)13:2\&lt;113::AIDADMA113\&gt;3.0.CO;2-H

Jang, J. S., Kim, H. G., Joshi, U. A., Jang, J. W., and Lee, J. S. (2008). Fabrication of $\mathrm{CdS}$ nanowires decorated with $\mathrm{TiO} 2$ nanoparticles for photocatalytic hydrogen production under visible light irradiation. Int. J. Hydr. Energy 33, 5975-5980. doi: 10.1016/j.ijhydene.2008.07.105

Jasim, K. E. (2011). "Dye sensitized solar cells-working principles, challenges and opportunities," in The Solar Cells-Dye Sensitized Devices, ed L. A. Kosyachenko (Janeza Trdine; Rijeka: InTech), $172-204$. the paper publication and CONACyT support. OM thanks the support of UNAM/DGAPA/PREI program 2019. The experimental support of the CNMN-IPN in the realization of the presented works is recognized as well.

\section{SUPPLEMENTARY MATERIAL}

The Supplementary Material for this article can be found online at: https://www.frontiersin.org/articles/10.3389/fmats. 2020.00006/full\#supplementary-material
Keşlioglu, K., Erol, M., Maraşli, N., and Gündüz, M. (2004). Experimental determination of solid-liquid interfacial energy for solid $\mathrm{Cd}$ in $\mathrm{Bi}-\mathrm{Cd}$ liquid solutions. J. Alloy. Comp. 385, 207-213. doi: 10.1016/j.jallcom.2004.05.010

Kolasinski, K. W. (2006). Catalytic growth of nanowires: vapor-liquid-solid, vapor-solid-solid, solution-liquid-solid and solid-liquid-solid growth. Curr. Opin. Solid State Mater. Sci. 10, 182-191. doi: 10.1016/j.cossms.2007.03.002

Kwak, W. C., Han, S. H., Kim, T. G., and Sung, Y. M. (2010). Electrodeposition of $\mathrm{Cu}(\mathrm{In}, \mathrm{Ga}) \mathrm{Se} 2$ crystals on high-density CdS nanowire arrays for photovoltaic applications. Cryst. Growth Des. 10, 5297-5301. doi: 10.1021/cg101157a

Kwak, W. C., Kim, T. G., Lee, W., Han, S. H., and Sung, Y. M. (2009). Templatefree liquid-phase synthesis of high-density CdS nanowire arrays on conductive glass. J. Phys. Chem. C 113, 1615-1619. doi: 10.1021/jp809365z

Lannin, J. S., Calleja, J. M., and Cardona, M. (1975). Second-order Raman scattering in the group-V b semimetals: $\mathrm{Bi}, \mathrm{Sb}$, and As. Phys. Rev. B Condens. Matter. 12:585. doi: 10.1103/PhysRevB.12.585

Lee, J. C., Lee, W., Han, S. H., Kim, T. G., and Sung, Y. M. (2009). Synthesis of hybrid solar cells using CdS nanowire array grown on conductive glass substrates. Electrochem. Commun. 11, 231-234. doi: 10.1016/j.elecom.2008.11.021

Lieber, C. M. (2003). Nanoscale science and technology: building a big future from small things. MRS Bull. 28, 486-491. doi: 10.1557/mrs2003.144

Liu, P., Singh, V. P., Jarro, C. A., and Rajaputra, S. (2011). Cadmium sulfide nanowires for the window semiconductor layer in thin film CdS-CdTe solar cells. Nanotechnology 22:145304. doi: 10.1088/0957-4484/22/14/145304

Ma, R. M., Wei, X. L., Dai, L., Huo, H. B., and Qin, G. G. (2007). Synthesis of CdS nanowire networks and their optical and electrical properties. Nanotechnology 18:205605. doi: 10.1088/0957-4484/18/20/205605

Marshall, R., and Mitra, S. S. (1964). Optically active phonon processes in CdS and ZnS. Phys. Rev. 134:A1019. doi: 10.1103/PhysRev.134.A1019

Nusimovici, M. A., and Birman, J. L. (1967). Lattice dynamics of wurtzite: CdS. Phys. Rev. 156:925. doi: 10.1103/PhysRev.156.925

Ouyang, L., Maher, K. N., Yu, C. L., McCarty, J., and Park, H. (2007). Catalyst-assisted solution- liquid- solid synthesis of CdS/CdSe nanorod heterostructures. J. Am. Chem. Soc. 129, 133-138. doi: 10.1021/ja066243u

Pan, Z., Rao, H., Mora-Seró, I., Bisquert, J., and Zhong, X. (2018). Quantum dotsensitized solar cells. Chem. Soc. Rev. 47, 7659-7702. doi: 10.1039/C8CS00431E

Schmidt, V., Wittemann, J. V., Senz, S., and Gösele, U. (2009). Silicon nanowires: a review on aspects of their growth and their electrical properties. Adv. Mater. 21, 2681-2702. doi: 10.1002/adma.200803754

Shiraki, Y., Shimada, T., and Komatsubara, K. F. (1974). Optical studies of deep-center luminescence in CdS. J. Appl Phys. 45, 3554-3561. doi: $10.1063 / 1.1663817$

Sun, J., and Buhro, W. E. (2008). The use of single-source precursors for the solution-liquid-solid growth of metal sulfide semiconductor nanowires. Angew. Chem. Int. Ed. 47, 3215-3218. doi: 10.1002/anie.200705142

Tang, J., Huo, Z., Brittman, S., Gao, H., and Yang, P. (2011). Solution-processed core-shell nanowires for efficient photovoltaic cells. Nat. Nanotech. 6:568. doi: 10.1038/nnano.2011.139

Thomas, D. G., and Hopfield, J. J. (1962). Optical properties of bound exciton complexes in cadmium sulfide. Phys. Rev. 128:2135. doi: 10.1103/PhysRev.128.2135

Varshni, Y. P. (1967). Temperature dependence of the energy gap in semiconductors. Phys. A 34, 149-154. doi: 10.1016/0031-8914(67)90062-6 
Wang, F., Dong, A., Sun, J., Tang, R., Yu, H., and Buhro, W. E. (2006). Solutionliquid-solid growth of semiconductor nanowires. Inorg. Chem. 45, 7511-7521. doi: 10.1021/ic060498r

Wang, L., Liu, Y., Jiang, X., Qin, D., and Cao, Y. (2007). Enhancement of photovoltaic characteristics using a suitable solvent in hybrid polymer/multiarmed CdS nanorods solar cells. J. Phys. Chem. C 111, 9538-9542. doi: 10.1021/jp0715777

Wang, Y., Meng, G., Zhang, L., Liang, C., and Zhang, J. (2002a). Catalytic growth of large-scale single-crystal CdS nanowires by physical evaporation and their photoluminescence. Chem. Mater. 14, 1773-1777. doi: 10.1021/cm01 15564

Wang, Y., Zhang, L., Liang, C., Wang, G., and Peng, X. (2002b). Catalytic growth and photoluminescence properties of semiconductor single-crystal ZnS nanowires. Chem. Phys. Lett. 357, 314-318. doi: 10.1016/S0009-2614(02)00530-4

Yang, Z. X., Zhong, W., Zhang, P., Xu, M. H., Deng, Y., Au, C. T., et al. (2012). Controllable synthesis, characterization and photoluminescence properties of morphology-tunable CdS nanomaterials generated in thermal evaporation processes. Appl. Surf. Sci. 258, 7343-7347. doi: 10.1016/j.apsusc.2012.04.010

Zervos, M., and Othonos, A. (2011). Gallium hydride vapor phase epitaxy of GaN nanowires. Nanoscale Res. Lett. 6:262. doi: 10.1186/1556-276X-6-262

Conflict of Interest: The authors declare that the research was conducted in the absence of any commercial or financial relationships that could be construed as a potential conflict of interest.

Copyright (c) 2020 Zayas-Bazán, Gutierrez Z-B, de Melo, Santana, SastréHernández, Aguilar-Hernández, Tufiño-Velázquez and Contreras-Puente. This is an open-access article distributed under the terms of the Creative Commons Attribution License (CC BY). The use, distribution or reproduction in other forums is permitted, provided the original author(s) and the copyright owner(s) are credited and that the original publication in this journal is cited, in accordance with accepted academic practice. No use, distribution or reproduction is permitted which does not comply with these terms. 